\title{
La dimensión generacional en la constitución del carácter individual: ¿Es posible hablar de un habitus de generación?
}

The generational dimension in the constitution of individual character: Is it possible to speak of a generational habitus?

Jorge Costa Delgado

Universidad de Alcalá jorge.costa@uah.es

DOI: https://doi.org/10.15366/bp2021.28.006

Bajo Palabra. II Época. No28. Pgs: 135-154 Orcid: https://orcid.org/0000-0001-6640-7549. 
Recibido: 25/09/2021

Aceptado: 12/11/2021

Este artículo forma parte del proyecto de investigación "Institución y Constitución de la Individualidad: Aspectos Ontológicos, Sociales y de Derecho” (inCOn). Referencia: PID2020-117413GA-I00 / AEI / 10.13039/501100011033).

\section{नivponges}

Resumen

Este artículo aborda un aspecto específico en la configuración del habitus, examinando si es posible identificar una dimensión generacional en él. Para ello, en primer lugar, comentaré los principales problemas epistemológicos que plantea el uso del concepto de generación. Posteriormente, los compararé con dificultades similares en la utilización del concepto de clase social, cuya asociación con el habitus está plenamente reconocida. Al final del artículo expondré, con la ayuda de Mauger y Mannheim, una propuesta de integración teórica para el uso del concepto de generación, con la que defiendo que sí es posible hablar de un habitus de generación.

Palabras clave: Generaciones, clases sociales, habitus, epistemología de las ciencias sociales, Bourdieu, Mannheim.

\section{Abstract}

This article addresses a specific aspect in the configuration of the habitus, asking whether it is possible to identify a generational dimension in it. To this end, I will first comment on the main epistemological problems posed by the use of the concept of generation. Subsequently, I will compare them with similar difficulties in the use of the concept of social class, whose association with the habitus is fully recognized. At the end of the article I will present, based on Mauger and Mannheim's works, a proposal of a theoretical integration for the use of the concept of generation, with which I argue that it is possible to speak of a $h a-$ bitus of generation.

Keywords: Generations, Social classes, Habitus, Epistemology of social sciences, Bourdieu, Mannheim. 
$\mathrm{E}$ l concepto de habitus de Pierre Bourdieu es una herramienta teórica creada para tratar de explicar cómo se producen las regularidades que se observan al analizar el comportamiento social de los individuos. El análisis sociológico a nivel macro reconstruye estas regularidades como estructuras sociales, con las que trata de explicar los fenómenos sociales que toma por objeto. Sin embargo, este análisis no resuelve por sí mismo la cuestión de la relación entre agente y estructura, o entre el individuo y la sociedad. Pierre Bourdieu, con su teoría del habitus, plantea un enfoque disposicional como respuesta a esa pregunta: los sujetos, durante su proceso de socialización, es decir, a partir de unas determinadas condiciones de existencia, incorporan una serie de disposiciones que son producto de dichas condiciones $\mathrm{y}$, al mismo tiempo, contribuyen a reproducirlas al generar prácticas afines a ellas. Estas disposiciones se van integrando de manera dialéctica en cada sujeto, esto es, a través de las disposiciones previamente incorporadas, que reaccionan ante nuevas experiencias. Así, el habitus define el conjunto sistemático de esas disposiciones integradas en un sujeto. En otras palabras, "es un conjunto de principios de percepción, valoración y de actuación debidos a la inculcación generada por el origen y la trayectoria sociales" (Martínez, 2017).

El enfoque disposicional permite a Bourdieu evitar la dicotomía entre libre albedrío y reproducción mecánica de las prácticas, afirmando una suerte de espontaneidad situada: una disposición ya incorporada percibe determinados aspectos en su exposición ante nuevas circunstancias, ubica al sujeto en una posición respecto a ellas y genera una respuesta entre un abanico limitado de posibilidades, que tienen un aire familia ligado a las condiciones de existencia de las que procede la disposición. Por otra parte, estas disposiciones operan a un nivel prerreflexivo: en su praxis, el sujeto no es consciente de cómo el habitus condiciona unas acciones que él mismo percibe como fruto de decisiones libres.

Más allá de esta breve introducción a los elementos centrales del habitus, el objetivo de este artículo no es analizar sus componentes ni reconstruir la génesis del concepto. Lo que pretendo es estudiar un aspecto específico en la configuración del habitus: la dimensión generacional. La utilización del concepto de habitus implica poner el foco de atención en los factores sociales más influyentes en el origen y la trayectoria social de los sujetos. Esto ha llevado a prestar atención a elementos considerados especialmente determinantes en la socialización primaria, como la clase social o el género. 
Las condiciones de existencia a las que se refieren estos conceptos son especialmente influyentes en fases muy tempranas de la socialización del sujeto: tienen, por tanto, una importancia crucial, ya que condicionan la adquisición de todas las disposiciones que se van integrando posteriormente en el habitus a través de experiencias posteriores. Así, aunque el habitus es un sistema de disposiciones particular en cada individuo, se puede hablar de un habitus de clase o de un habitus de género, en la medida en que similares experiencias de clase o género suponen similares disposiciones incorporadas y, por tanto, una praxis social parecida -aunque nunca idéntica- en los aspectos condicionados por estos factores. El concepto de generación tiene una larga tradición en filosofía y ciencias sociales, pero existe una discusión en cuanto a su potencial para agrupar con garantías, es decir, con suficiente precisión y rigurosidad, condiciones de existencia similares. Pero incluso si fuera posible, al menos en determinadas circunstancias, delimitar con garantías la extensión social de una generación, jes la generación un factor de socialización a un nivel similar a la clase social o el género? En definitiva, ¿es posible hablar también de un habitus de generación?

Para responder a esta pregunta comentaré, en primer lugar, los problemas epistemológicos que considero que plantea el concepto de generación en sus usos más extendidos: la extensión social y temporal de una generación, la tautología de la referencia biológica asociada al concepto y la selección arbitraria de factores determinantes de una generación. En un segundo apartado, tras una muy breve exposición de las principales características del concepto de clase social a partir de Erik Olin Wright (2018), analizaré si los problemas epistemológicos antes citados pueden aparecer también en el uso de este concepto. Para el caso de la referencia biológica, por sus especiales características y su frecuente uso asociado al concepto de habitus, introduciré puntualmente el concepto de género en la comparación. A partir de esta comparación, trataré de defender que los problemas asociados al uso del concepto de generación no son exclusivamente suyos, sino que responden a cuestiones epistemológicas de más amplio alcance que afectan también, con sus matices específicos, al uso de otros conceptos. Por último, concluiré con una breve exposición de lo que considero que pueden ser los usos epistemológicamente más productivos y fiables del concepto de generación, defendiendo, además, que es perfectamente compatible -aunque no de manera exclusiva- con la teoría de los campos y con el concepto de habitus de Pierre Bourdieu.

\section{Los problemas epistemológicos del concepto de generación}

El concepto de generación se encuentra en una situación paradójica dentro de las ciencias sociales. Por un lado, su uso es muy frecuente, tanto en el ámbito 
de la divulgación, es decir, en una producción realizada por especialistas para un público amplio de no especialistas, como en las periodizaciones con las que, implícita o explícitamente, los intelectuales organizan las genealogías de sus propias disciplinas y se ubican ellos mismos en la tradición a la que pertenecen. Por tanto, podría decirse que el concepto de generación ocupa un lugar importante en el sentido común de los científicos sociales y en la contribución que las ciencias sociales hacen al sentido común de la población en general. ${ }^{1}$ Por otro lado, no obstante, el concepto de generación no goza de buena prensa epistemológica (Mauger, 2011:4-11 y Mauger, 2015:19-22): salvo en el caso de una aplicación muy delimitada en un sentido estadístico (cohortes generacionales) o biológico (generaciones de individuos dentro de un mismo linaje), con frecuencia se discute su capacidad explicativa y se critica su uso poco controlado. ${ }^{2}$

No voy a detenerme en explicar los distintos significados incluidos en el campo semántico de lo generacional, ya que no es el objetivo de este artículo. Tan solo lo haré brevemente cuando sirva al propósito de mi argumentación. ${ }^{3}$ Lo que me interesa es destacar los problemas más importantes que presenta el concepto de generación desde un punto de vista epistemológico.

\subsection{La extensión social de una generación}

El uso de denominaciones o etiquetas generacionales que atraviesan todo el universo social supone una serie de implícitos difícilmente justificables, salvo en coyunturas históricas muy excepcionales (Mauger, 2015:47-71). Tomemos el ejemplo de la llamada millennial generation. Aunque no existe acuerdo entre la enorme cantidad de publicaciones de muy variado signo dedicadas a ella, se suele ubicar en dicha generación a los nacidos entre los años 1980 y 2000. La extensión geográfica varía según el estudio: desde un país hasta el conjunto de la población mundial, pasando por divisiones geográficas intermedias o difusos marcos culturales comunes. Con frecuencia, el criterio que determina tal extensión social no procede de un análisis previo de la pertinencia del concepto de generación en relación con el objeto de estudio, sino a características circunstanciales del mismo. Por ejemplo: las fuentes

\footnotetext{
${ }^{1}$ Piénsese en la popularidad de términos como Millennial, Generación X, Generación Z, Baby Boomers o Generación ni-ni.

2 Entre los autores a los que Mauger atribuye una visión crítica con el concepto de generación se encuentran: Durkheim, Halbwachs, Lucien Febvre, Chamboredon o el propio Bourdieu.

3 Para un análisis extendido sobre las distintas nociones, categorías y conceptos asociados al campo semántico de lo generacional, véase el libro ya citado de Mauger (2015) y Martín Criado (1998).
} 
estadísticas disponibles, la difusión de los productos culturales cuyo consumo se considera signo de pertenencia generacional, el acceso a las tecnologías señaladas como características de la zona de fechas en cuestión, o el grado de impacto de acontecimientos históricos considerados emblemáticos del período. Sea cual sea el criterio elegido, este se adapta a una etiqueta previa, definida con rasgos muy generales y moldeables, que resulta rentable en términos publicitarios: la propia difusión del término - millennials- hace atractivo su uso. Pero en la medida en que su valor publicitario y lo intuitivo de su contenido se convierten en los criterios principales para su utilización, se pierde rigurosidad al obviarse un cuestionamiento previo acerca de su pertinencia en relación con cada objeto de estudio específico.

Utilizar una denominación generacional como esta para caracterizar a una sección transversal a toda la sociedad de individuos de edades cercanas implica asumir que esos individuos tienen una serie de características relevantes en común que los diferencian, conjuntamente, de otras secciones de edades diferentes. Aquí la palabra relevante debe entenderse en términos epistemológicos, es decir, estas características tendrían cierto potencial explicativo a la hora de comprender el comportamiento social de estos individuos; al menos mayor potencial que las categorizaciones que posibilitan otros conceptos disponibles en el instrumental teórico de las ciencias sociales, por ejemplo, clase social y género, de los que hablaré más adelante. El peligro, en este caso, consiste, en palabras de Mauger (2011:155) en "alejar a los próximos y acercar a los que están muy alejados socialmente" o, según Bourdieu (1980:145), en "subsumir bajo el mismo concepto universos sociales que no tienen prácticamente nada en común”. Además, esta idea de una sección transversal de toda la sociedad que tiene una similar representación del mundo supone una imagen holística de la sociedad: cada época tendría un "espíritu del tiempo", común a todos los individuos formados en ese "ambiente", que se expresaría en determinados objetos sociales privilegiados. Con frecuencia, esta representación se construye proyectando la imagen de un grupo social específico al conjunto de la categoría generacional, lo cual introduce un sesgo sociocéntrico evidente.

Algunos autores han partido de esta representación holística de la sociedad para tratar de explicar el cambio social recurriendo a la dinámica de la sucesión generacional. Desde este enfoque, presente por ejemplo en En torno a Galileo, de Ortega y Gasset (2004-2010, VI: 385-420), la propia lógica de la transmisión cultural y los desajustes parciales que se producen en esta, debido a la aparición de nuevos problemas y a los conflictos por el ritmo de sucesión en los espacios de poder, serían el principal motor de las transformaciones sociales. Esto llevó a Ortega a intentar establecer un ritmo regular de ańos para tratar de establecer grandes series generacionales a lo largo de la historia. 


\subsection{La extensión temporal de una generación}

En los orígenes científicos del concepto de generación, a mediados del siglo XIX (Mannheim, 1993 y Marías, 1967), una de las ambiciones teóricas que contribuyeron a su desarrollo fue la de encontrar una herramienta que pudiera medir con garantías la regularidad del cambio social. Es lo que impulsó la evolución del concepto en la tradición que Mannheim denomina como positivista. La histórico-romántica se corresponde más bien con esa perspectiva holística que mencionaba en el apartado anterior: cada generación social expresa su particular mirada sobre el mundo, su lugar en la historia de la Humanidad. Si bien ambas tradiciones pueden combinarse, tal y como se observa en la síntesis de Ortega citada anteriormente. Volviendo a la tradición positivista, uno de sus rasgos más característicos, en consonancia con su preocupación por establecer una ley científica del cambio social, consiste en proponer series de zonas de fechas, con intervalos regulares, aplicables a cualquier contexto histórico. Estos autores encuentran distintas razones para argumentar a favor de intervalos de quince, veinticinco o treinta años, en los que cabría encajar la evolución de la historia de la filosofía, las transformaciones políticas, las corrientes culturales o el progreso civilizatorio en general.

Lo que subyace a esta posición teórica es una metáfora que compara la evolución de una sociedad -o de parte de ella- con las fases del desarrollo biológico y cognitivo que tiene un individuo. De la misma manera que se considera posible reconstruir científicamente el ciclo de madurez de cualquier ser humano tomado individualmente (véanse las teorías de Piaget (1979) sobre el desarrollo cognitivo o de Kohlberg (2010) sobre el desarrollo moral), se cree posible encontrar un esquema teórico que permita explicar un ritmo regular de evolución "natural" de las sociedades humanas. El problema es que no hay nada que justifique esa analogía: las lógicas que permiten explicar la evolución de una sociedad no son las mismas que las que rigen el desarrollo de un individuo y, además, incluso a nivel individual, estas lógicas son parciales - no es lo mismo el desarrollo cognitivo que el moral-y variables según diferentes contextos históricos y socio-culturales. ${ }^{4}$ Así que cualquier propuesta que sugiera un intervalo generacional regular transhistórico parte de un a priori, aunque con frecuencia no se explicite: considerar que dicho intervalo se aproxima a la ley natural que regula el ritmo de las transformaciones sociales en el ser humano.

\footnotetext{
${ }^{4}$ Hasta qué punto hay lógicas universales del desarrollo cognitivo y moral del ser humano es una cuestión en discusión. Pero incluso quienes defienden que estas existen, admiten ritmos variables en función del contexto cultural y de las condiciones sociales en que se desarrolla un individuo.
} 
Por otra parte, el uso del concepto de generación es ineludiblemente relacional e invita, por sí mismo, a establecer una serie de generaciones: una generación posee unas características propias que no son sustantivas, sino que cobran sentido en relación con su ausencia o modificación en una generación anterior o posterior. Por lo tanto, definir una generación, sea cual sea su acepción, implica definir unas fronteras temporales frente a otras generaciones: cuándo comienza y cuándo termina. No obstante, nada justifica que esa sucesión deba seguir un ritmo regular. Retomando el ejemplo de la Generación millennial, su definición conlleva la identificación de antecesoras -Generación X- y sucesoras -Generación Z-. Pero otro ejemplo puede ser más ilustrativo de esta característica del concepto. La construcción de una categoría como jóvenes "ni-ni" -que ni estudian ni trabajan, procedente del inglés "NEET" (Not in Education, Employment or Training) - supone una doble delimitación: frente a los adultos, a los que no se supone en edad formativa, y frente a otros jóvenes que sí estudian o trabajan y, por tanto, se encontrarían mejor situados socialmente en la transición entre la juventud y la madurez. La categoría tiene sentido en la medida en que hay un grupo social relativamente amplio o significativo con estas características y que, por tanto, merece atención. Sin embargo, cuando la denominación se desliza desde "jóvenes ni-ni” a "generación ni-ni” aparecen las dos características del concepto que acabamos de mencionar: en primer lugar, se considera que la situación de este grupo particular de jóvenes es sintomática del conjunto de la juventud de una sociedad determinada, difuminándose la frontera entre jóvenes ni-ni y los que no lo son; ${ }^{5}$ en segundo lugar, se construye una generación previa como contraste con la "generación ni-ni", marcada con características y/o valores opuestos: acceso temprano al trabajo, éxito académico, esfuerzo, integración social, etc.

\subsection{La tautología de la referencia biológica}

La sucesión biológica de individuos es un recurso tentador a la hora de explicar el cambio o la reproducción social porque ofrece un soporte natural para fijar una "ley científica" que permita estudiar y predecir las transformaciones sociales. El problema es que la sucesión de padres a hijos no se produce de manera simultánea en el conjunto de la sociedad, sino con temporalidades diferentes en el seno de cada unidad familiar. Indudablemente, el hecho de la caducidad de la vida

\footnotetext{
5 Estos últimos quedan como excepciones frente a la dinámica generacional "normal", o bien quedan "contaminados" por los primeros, pese a no compartir su situación. Así, supuestamente, todos tendrían una serie de costumbres, actitudes morales, prácticas laborales, etc. comunes o con un cierto aire de familia.
} 
humana plantea la pregunta acerca de la manera en que se trasmite la cultura y se reproducen las estructuras sociales más allá de la vida de sus agentes, pero no aporta automáticamente ninguna explicación acerca del ritmo temporal de dicha reproducción o de la regularidad de sus posibles transformaciones. De hecho, hay quien especula teóricamente con que el alargamiento indefinido de la vida humana podría conducir a un estancamiento cultural, ya que desaparecería el estímulo creativo que introduce la base biológica de la sucesión generacional, es decir, la muerte. ${ }^{6}$ Sin embargo, dejando a un lado las dudas acerca de la utilidad de estas discusiones, no parece que el espectacular crecimiento de la esperanza de vida a nivel mundial en los últimos dos siglos haya ido acompañado de una mitigación del ritmo de las transformaciones sociales; más bien al contrario. Es innegable que la biología del ser humano -y sus eventuales modificaciones- condiciona su vida social y establece un marco a partir del cual se realiza su producción cultural, pero no es posible establecer explicaciones causales a partir de lo natural sin atender a las lógicas específicas de lo social.

Dentro de este apartado dedicado a la tautología de la referencia biológica también se encuentra la naturalización de las edades sociales. Esto ocurre cuando se considera que las fases de la vida en que se divide la trayectoria de una persona en un contexto social determinado, delimitadas por una franja aproximada de edades cronológicas o de ritos de paso, poseen una serie de características "naturales". Y eso en un doble sentido: primero, asumiendo que tales fases -las edades sociales- son universales, lo que supone asumir, contra toda evidencia empírica, que categorías como infancia, adolescencia, juventud, madurez o senectud no varían históricamente e incluso dentro de una misma sociedad. Segundo, derivando de las transformaciones biológicas que se producen en el cuerpo humano con el curso de la edad (crecimiento, madurez, deterioro...) una serie de características y comportamientos que expresarían una esencia característica de cada edad. Así, por ejemplo, la juventud sería rebelde e idealista y la vejez conservadora y pragmática.

\subsection{La selección arbitraria de factores determinantes de una generación}

Un último problema destacable es el control epistemológico de los criterios utilizados para seleccionar los factores relevantes en la caracterización de una ge-

\footnotetext{
${ }^{6}$ Esto que en Ortega (2004-2010, III:561-565) es solo una metáfora que le permite mostrar, por reducción al absurdo, la necesidad social de la sucesión generacional se ha convertido dentro de corrientes como el transhumanismo o la bioética en un objeto de discusión que merece la atención de una filosofía meramente especulativa. Véase Gyngell (2015).
} 
neración. El aire de familia que se desprende de un determinado grupo, o que proyecta sobre él la mirada de quien lo construye como objeto de estudio, se toma con facilidad como un dato evidente por sí mismo. El objeto así construido se descontextualiza y se analiza por separado, como si pudiera explicarse sin hacer referencia a otros factores sociales que contribuyen a la génesis empírica o epistemológica del grupo. De esta manera, las características elegidas para la generación se constituyen como un arbitrario teórico que se da por sentado, atribuyéndose al "espíritu del tiempo", a una evolución necesaria propia del ámbito al que se aplica el concepto o a la huella que el azar social o natural ha imprimido en algunos individuos.

Un buen ejemplo, muy habitual en el autoanálisis de los medios intelectuales, es la selección de epónimos generacionales, ya sea de la producción cultural en su conjunto o de disciplinas particulares. Así, se parte de una selección de grandes nombres característicos de una época, cuya vida y obra expresarían lo esencial de la vida intelectual o del aporte de la disciplina en ese período. Estudiándolos a ellos, solemos pensar, tenemos una imagen aproximada del período: porque no podemos estudiarlos a todos o porque los demás, si los hubiera, por ser menos brillantes no tienen información relevante que aportarnos. Sin embargo, este procedimiento se ahorra preguntas que son epistemológicamente fundamentales: ¿qué hace "grandes" a esos nombres?, ¿es eso que los hace "grandes" también epistemológicamente relevante para nuestro estudio?, ¿cómo se produce la mediación entre las condiciones sociales de constitución del grupo -objetivamente presentes en el grupo o subjetivamente introducidas por quien lo estudia- y lo que este expresa como tal?

\section{2. ¿Son estos problemas epistemológicos específicos de las generaciones? Una comparación con el caso de la clase social}

Pese a los problemas señalados, que además no están presentes en todos los usos de las generaciones, una crítica centrada exclusivamente en un concepto tiende a subrayar sus defectos o limitaciones y se corre el riesgo de atribuirle problemas epistemológicos que tienen un alcance más general, extendiéndose también al uso de otros conceptos y categorías. Veamos si es este el caso, a partir de una comparación del concepto de generación con el concepto de clase social, para valorar si las críticas recién señaladas al uso del primero pueden aplicarse también a los dos últimos. Como ya he indicado, introduciré también una breve mención al concepto de género en el apartado dedicado a la tautología de la referencia biológica. 


\subsection{La validez epistemológica del concepto de clases sociales, según Erik Olin Wright}

En la introducción a su obra Comprender las clases sociales, Erik Olin Wright (2018:12) plantea una aproximación no dogmática al concepto de clase social, es decir, alejado de la "gran batalla de los paradigmas". Desde este punto de vista, el uso del concepto de clase social por parte de determinadas tradiciones teóricas, como la marxista, no revelaría una realidad esencial subyacente validada por un análisis teórico previo. Al contrario, las "distintas tradiciones tienen valor científico en la medida en que sus pretensiones estén justificadas", esto es, en la medida en que se demuestre que los conceptos que movilizan identifican y ayudan a explicar "mecanismos reales relevantes para una serie importante de problemas". En otras palabras, si bien existe un trabajo específico de depuración lógica del concepto, la validez epistemológica de un concepto o de una teoría se mide por su rendimiento empírico: su capacidad de explicar la realidad. Por lo tanto, no tiene sentido mantener una discusión acerca de la validez general de un concepto, sino de la productividad de sus usos en relación a contextos empíricos y objetos de estudio específicos.

Wright (2018:14) distingue tres enfoques teóricos o usos del concepto de clase social que tienden a asociarse, aunque no de manera exclusiva, a tres tipos de procesos causales relacionados con el análisis de clase: el enfoque de los atributos individuales de la clase, el del acaparamiento de posibilidades y el de la dominación $y$ explotación. El primero presta especial atención a la manera en que se conectan los atributos individuales de las personas con las condiciones materiales en las que viven: las similitudes entre estos dos tipos de elementos permiten identificar distintas agrupaciones de individuos que denominamos clases sociales. La pregunta clave de este primer enfoque sería: ¿cómo se adquieren los atributos que determinan la posición de clase? El segundo enfoque se centra en la existencia de mecanismos de exclusión que filtran el acceso de los individuos a posiciones sociales que garantizan recursos económicos. A diferencia del primer enfoque, en este caso se establece una relación causal entre quienes disfrutan de una posición privilegiada y quienes no lo hacen: los primeros la disfrutan porque los citados mecanismos excluyen a los segundos (Wright, 2018:20). Algunos de estos mecanismos de exclusión, variables según el contexto, serían los títulos académicos, los derechos de ciudadanía, la racialización y, cuestión especialmente relevante en las sociedades capitalistas, la propiedad privada de los medios de producción. En este caso, la pregunta central es: ¿qué relación existe entre quienes poseen unos determinados recursos y quienes carecen de ellos? Por último, el tercer enfoque analiza el vínculo causal existente no solo entre posiciones sociales que dan acceso a recursos, sino en la propia actividad económica. La dominación, explica Wright (2018:21) permite controlar las acti- 
vidades de otros; la explotación permite, además, extraer un beneficio económico de ello. De esta manera se introduce una cuestión normativa, ya que se evalúa la desigual capacidad de los sujetos -su desigual libertad o autonomía- para definir las condiciones en que obtienen sus recursos económicos. Desde este punto de vista, en las sociedades capitalistas existe una división fundamental: la posesión y el control de los medios de producción; aunque existen otras jerarquías secundarias asociadas a esta. Aquí, la pregunta clave es: ¿cómo se generan las condiciones para la dominación/explotación?

\subsection{Una comparación entre clases sociales y generaciones}

Como se ve, distintos usos de los conceptos permiten distintas aproximaciones a la realidad empírica, con un rendimiento variable en función del contexto. ¿Pero qué ocurre si tratamos de cuestionar estos usos del concepto de clase social a partir de los problemas epistemológicos señalados anteriormente para el concepto de generación?

En primer lugar, al igual que las generaciones, las clases sociales requieren una delimitación espacial y temporal. En un sentido muy básico, que no siempre se tiene en cuenta, las divisiones de clase no son idénticas en España o en Estados Unidos, ya que los factores sociales relevantes para discriminar el acceso de los individuos a los recursos económicos pueden ser distintos o tener diferente peso. Por lo tanto, tratar de identificar un concepto de clase obrera o de burguesía válido universalmente puede tener sentido desde el punto de vista de la coherencia lógica o de la comparación entre distintos contextos sociales, pero sin duda tiende a repercutir negativamente en el potencial heurístico de dicho concepto a la hora de aplicarlo a una realidad social específica. Asimismo, la influencia de los distintos factores que permiten identificar las fronteras entre clases o fracciones de clases sociales tampoco pueden establecerse a priori: es cierto que la centralidad de la propiedad de los medios de producción, característica de la tradición marxista, como señala Wright (2018: 21-24), permite explicar una parte importante de las desigualdades económicas en las sociedades capitalistas, pero eso no quiere decir que las explique todas. Y menos aún, que sea a través de este factor específico como se exprese la influencia de lo económico en otras actividades sociales. Todo ello depende, al igual que en el caso del concepto de generación, del rendimiento heurístico que tenga el concepto en relación a un contexto empírico determinado, lo que exigirá adaptar parcialmente el uso a los materiales y compararlo con otros conceptos y marcos teóricos posibles si quiere ser científicamente valioso. 
En cuanto a la dimensión temporal, también con las clases sociales se corre el riesgo de esencializar una imagen a partir de un ejemplo histórico, ya sea real o figurado. Por ejemplo, en el debate intelectual actual encontramos autores que proyectan una imagen idealizada de la clase obrera que procede de otras épocas o de su particular interpretación de la tradición marxista, ante la cual palidece cualquier intento de agrupar teórica o políticamente a las personas que trabajan en las condiciones realmente existentes.

A la hora de comparar el problema de la tautología de la referencia biológica presente en el uso del concepto de generación, la analogía resulta mucho más evidente en el caso del concepto de género, que desde su origen (Oakley, 1972) trata precisamente de marcar las distancias entre lo biológico y la construcción social. Este esfuerzo teórico y político por escapar de una naturalización de las desigualdades sociales es previo al propio concepto ${ }^{7}$ y todavía continúa en discusión, por ejemplo, a partir de la crítica de Judith Butler (2007) a los condicionantes sociales implícitos en la categoría biológica del sexo. No obstante, en algunos usos - no poco extendidos- del concepto de clase social cabe encontrar una forma de esencialización paradójicamente social, que ha sido objeto de crítica dentro de la propia tradición marxista (Laclau y Mouffe, 2015; Wright, 2014): la consideración -con diversos grados de mediación- de la determinación de la economía sobre todos los aspectos de la vida social como un a priori epistemológico.

Por último, en lo referente a la selección arbitraria de factores determinantes de una generación, el riesgo de la extensión arbitraria de propiedades a partir de una representación sesgada de una clase social en particular presenta similitudes evidentes. Puede ocurrir de dos formas: 1) tomando una imagen real -entiéndase epistemológicamente bien fundada- de un sector específico de una clase y proyectándola sobre el conjunto, invisibilizando a quienes no encajan en ella o representando a esos sectores excluidos desde la carencia en relación al prototipo establecido; 2) a partir de una situación coyuntural de clase entendida según el primero de los enfoques descritos por Wright, es decir, como una asociación entre atributos individuales y condiciones materiales de los sujetos, se toman arbitrariamente una serie de atributos como signo de pertenencia a una clase social y se desligan de un análisis riguroso de las condiciones materiales de existencia. De esta manera, se designa a la clase obrera por exhibir gustos musicales considerados "obreros" o a la burguesía por practicar formas de relación familiar "burguesas", invirtiendo la relación causal que se encuentra en el origen del análisis de clase.

${ }_{7}$ De hecho, puede decirse que forma parte del núcleo esencial de la tradición feminista desde sus orígenes. 
Estas comparaciones muestran solamente las similitudes entre algunos usos de estos dos conceptos y no pretenden ser una exposición exhaustiva, que no tiene cabida aquí. Su sentido en este artículo consiste en mostrar que las críticas a determinados usos del concepto de generación, pese a ser legítimas y a estar ligadas a características específicas del mismo -en particular, dificultades relacionadas con su atención preferente a la temporalidad-, responden al mismo tiempo a cuestiones epistemológicas de más largo alcance, que comparten con otros conceptos de curso habitual en ciencias sociales. En última instancia, las dificultades aquí mencionadas tienen que ver con "una tensión epistemológica irresoluble entre las dimensiones teórica y empírica, que es característica de las ciencias sociales" (Passeron, 2006:601), de manera que una excesiva insistencia en asegurar la coherencia lógica de un concepto o fijar su lugar en un marco teórico sistemático pone en riesgo su capacidad explicativa al aplicarlo a materiales empíricos. A la inversa, la pretensión de registrar detalladamente materiales empíricos "tal y como se presentan", sin ningún intento de abstracción controlada de sus propiedades, condena a la falta de sentido o, más frecuentemente, a la extrapolación abusiva de conclusiones a partir de materiales fragmentarios.

\section{3. ¿En qué circunstancias puede ser productivo considerar una dimensión del babitus específicamente generacional?}

Retomemos ahora las preguntas planteadas en la introducción, previas a la descripción y comparación de estos problemas epistemológicos: ¡tiene sentido hablar de un habitus de generación?; ¿en qué circunstancias? Para responder a estas preguntas utilizaré un esquema teórico que ya he apuntado en La educación politica de las masas (Costa Delgado, 2019) aplicado a la Generación del 14, y que se apoya fundamentalmente en los trabajos de Mannheim (1993) y Mauger (2011 y 2015).

Creo, basándome en Mauger (2011:11-17), que el uso epistemológicamente más productivo del concepto de generación debe ir acompañado, en la mayor parte de los casos, de su aplicación a campos sociales bien delimitados, no a una sección transversal del conjunto de las sociedad. Así, una primera delimitación del objeto de estudio obliga a explicitar los criterios que fundan la selección de factores y atributos que recoge la referencia generacional: aquellos que son relevantes para entender la lógica específica del campo en cuestión. Una segunda operación llevaría a describir y explicar el funcionamiento de los mecanismos sociales que contribuyen a que los sujetos estudiados interioricen y reproduzcan las lógicas sociales que rigen el campo. Por último, y esto es lo más característico y productivo del concepto de generación, se trataría de identificar variaciones temporales en los dos aspectos anteriores (propiedades sociales 
relevantes para entender la lógica del campo en cuestión y mecanismos de configuración subjetiva de los individuos que se integran en dicho campo), diferenciando las transformaciones sustanciales de aquellos conflictos por la sucesión de posiciones en donde cambian los protagonistas individuales, pero permanece la misma lógica de fondo. O, en palabras de Ortega y Gasset (2004-2010, VI: 417-419), se trataría de captar la diferencia entre "cambiar el mundo o solo cambiar algo en el mundo".

Obviamente, la descripción que acabo de hacer se sirve de la teoría sociológica de Bourdieu para expresar las operaciones epistemológicas requeridas: entran en juego, particularmente, la idea de autonomía relativa y siempre en conflicto de los campos sociales (Sapiro, 2019), el concepto de habitus como herramienta para explicar la mediación entre las estructuras sociales y las prácticas subjetivas, y la propia idea de la configuración del habitus en sucesivas capas, resultado de una incorporación dialéctica de disposiciones a través de la experiencia biográfica de cada sujeto (Bourdieu, 2008:85-105). Sin embargo, no considero que el uso propuesto del concepto de generación, que especificaré a continuación, quede restringido a este marco teórico específico: desde otras tradiciones y con otros conceptos que permitan aprehender la relación entre las dinámicas propias de espacios sociales delimitados y su "exterior", por un lado, y explicar las mediaciones entre estructura y agentes, por otro, el esquema seńalado sigue siendo enormemente productivo.

En fin, ya sea desde esta u otra tradición teórica, la categoría de "modo de generación" permite recoger la idea que se deriva de las operaciones señaladas: se trata de describir cómo se generan -se producen- sujetos desde la óptica del espacio social estudiado. Es por esto que dicho espacio social debe estar lo suficientemente delimitado como para poder identificar una lógica relativamente sistemática, que no sería sostenible a nivel del conjunto de la sociedad. ${ }^{8}$

¿Pero qué ocurre con las jerarquías epistemológicas que podemos establecer entre las transformaciones temporales que se producen dentro de un modo de generación? ¿Estamos condenados prestar atención únicamente a los grandes cambios estructurales? Eso nos llevaría a dejar de lado transformaciones sociales de menor calado estructural, pero con un impacto y relevancia social en absoluto despreciables... De hecho, estos cambios menores frecuentemente juegan un rol muy importante en una reconstrucción de largo aliento de los cambios producidos en los modos de generación. Para estudiarlos, podemos acudir a dos categorías procedentes de Mannheim (1993): unidad generacional y conjunto o conexión genera-

\footnotetext{
${ }_{8}$ En esto sigo a Passeron (2006:196-197), que no considera que en las sociedades complejas pueda identificarse una lógica de reproducción social de conjunto, sino lógicas o sistemas parciales que se relacionan entre sí, pero nunca de manera absolutamente coherente y funcional, y con frecuentes contradicciones, que Passeron, tratando de evitar una teleología hegeliana, describe como "externas" y no internas.
} 
cional. La primera, unidad generacional, permite especificar maneras distintas de concretar -diacrónica o sincrónicamente- un modo de generación. De nuevo recurriendo a Ortega, nos permite hablar de algo que cambia en un mundo (un campo social) sin confundirlo con un cambio de mundo (una ruptura en el modo de generación). La segunda, conexión generacional, permite describir las coyunturas en que sujetos que se mueven en campos sociales distintos interactúan de manera más o menos sostenida en el tiempo en torno a problemas compartidos. Nos sirve, por tanto, para evitar considerar a los campos sociales como espacios completamente autorreferenciales y abrir una puerta epistemológica al análisis de sincronizaciones parciales entre campos, de las influencias de unos sobre otros, o incluso de procesos de eventual pérdida de autonomía de un determinado campo social.

He dicho al principio de este apartado que el uso más productivo del concepto de generación debía asociarse, en la mayor parte de los casos, a campos sociales bien delimitados. ¿¿Pero qué ocurre con los casos extraordinarios? ¿Acaso no existen acontecimientos históricos de tal relevancia que marcan al conjunto de la población? ¿No sería posible, en esos casos, estudiar las posibles diferencias en términos de edad que deja esa marca histórica perdurable? Efectivamente, cabe hablar de acontecimientos generacionales, es decir, de acontecimientos históricos que dejan una huella diferencial según la edad de los sujetos que participan o se ven afectados por ellos. Podemos integrar estos procesos en el esquema teórico que acabo de exponer para los casos habituales en campos sociales delimitados. Para ello, recurriré a otra categoría de Mannheim: la "posición generacional". El sociólogo húngaro entiende por posición generacional el vínculo potencial que une a individuos de una misma edad social en un marco cultural determinado, por ejemplo: jóvenes urbanos y campesinos. Este vínculo potencial solo se hace efectivo cuando esos individuos participan en un "destino común" (Mannheim, 1993:222). En mi esquema, la posición generacional alude a la posibilidad siempre abierta de trasladar o imponer una conexión generacional -o incluso la lógica específica de un modo de generación- al conjunto de individuos de una misma edad dentro de una sociedad determinada. En casos extremos, esta traslación y/o imposición puede aplicarse al conjunto de la población. Sin embargo, estos acontecimientos generacionales, que también pueden definirse como sincronizaciones temporales entre las lógicas de distintos campos, son raros y precarios, al menos en sociedades complejas. Después de una corta fase de sincronización, se reconstituyen las lógicas específicas de cada campo: el acontecimiento generacional deja la huella de una experiencia compartida con unos efectos que se retraducen posteriormente a la lógica específica de cada campo. Mauger (2015:64) señala algunos ejemplos de este tipo de acontecimientos: guerras, revoluciones políticas, transformaciones a gran escala del sistema educativo y, ańado yo, grandes crisis económicas. 
Todas las categorías incluidas en este esbozo de teoría de las generaciones permiten analizar con matices y rigurosidad el elemento más característico que recoge cualquier uso del concepto de generación: la huella que deja en la configuración de la subjetividad de cualquier ser humano el hecho diferencial de haber vivido una experiencia relevante y duradera en un ámbito social determinado y a una edad en particular. El requisito de que sea "relevante y duradera", ya sea por su extensión en el tiempo o por la perdurabilidad de sus efectos, así como la importancia del orden temporal en que se produce -dada la configuración dialéctica del habitus en Bourdieu- permiten hablar de una dimensión generacional del habitus. Con ello, podríamos agrupar rasgos similares de habitus individuales y estudiar tendencias generacionales en la medida en que dichos rasgos sean producto de experiencias similares y no una selección arbitraria de analogías tan solo aparentes.

\section{Conclusión}

Después de este recorrido por los retos epistemológicos que plantean generaciones y clases sociales, y de esta propuesta de integración teórica de los distintos usos del concepto de generación, podemos retomar las dos preguntas que planteé al principio del artículo. A la primera -jes la generación un factor de socialización a un nivel similar a la clase social o el género? - cabe responder un sí con matices. Por un lado, los principales problemas epistemológicos que plantea el uso del concepto de generación, pese a sus especificidades, no se alejan de las dificultades que plantean los conceptos de clase social y género; por tanto, no cabe considerar al primero menos fiable a priori que a los otros dos. Por otra parte, el uso epistemológico del concepto de generación que defiendo va necesariamente acompañado de un análisis detallado de los espacios sociales a los que se aplica y de las formas en que estos configuran las subjetividades de los individuos que participan en ellos. Una generación, por así decirlo, no se sostiene por sí sola: introduce una dimensión temporal en el análisis de un objeto que, de otra manera, pierde esa riqueza y tiende a proyectar una imagen fija, sincrónica de su funcionamiento. Por ello, tiene un cierto carácter auxiliar que no está presente en el caso de las clases sociales o el género. En cuanto a la segunda - ¿es posible hablar también de un habitus de generación? -, coincido con Mauger (2011: 124-155) en que sí es posible, conveniente y que además puede hacerse integrando los aportes teóricos de la tradición bourdiesiana y Mannnheim; si bien no considero que dicha integración teórica particular sea una condición ineludible para un uso epistemológicamente rico del concepto de generación, que sigue siendo compatible con otros marcos teóricos. 


\section{REFERENCIAS BibLIOGRÁFICAS}

Bourdieu, P. (1980). La “jeunesse” n'est qu'un mot. Questions de sociologie. Minuit.

Bourdieu, P. (2008). El sentido práctico. Siglo XXI.

Butler, J. (2007). El género en disputa. El feminismo y la subversión de la identidad. Paidós.

Costa Delgado, J. (2019). La educación politica de las masas. Capital cultural y clases sociales en la Generación del 14. Siglo XXI.

Gyngell, C. (2015). The Ethics of Human Life Extension: The Second Argument from Evolution. The Journal of Medicine and Philosohpy: A Forum for Bioethics and Philosophy of Medicine, 40, 6, pp. 696-713.

Kohlberg, L. (2010). De lo que es a lo que debe ser. Cómo cometer la falacia naturalista y vencerla en el estudio del desarrollo moral. Prometeo Libros.

Laclau, E. y Mouffe, C. (2015). Hegemonía y estrategia socialista. Hacia una radicalización de la democracia. Siglo XXI.

Mannheim, K. (1993). El problema de las generaciones. Revista Española de Investigaciones Sociológicas, 62, pp. 193-242.

Marías, J. (1967). El método histórico de las generaciones, Revista de Occidente.

Martín Criado, E. (1998). Producir la juventud. Crítica de la sociología de la juventud. Istmo.

Martínez García, J. S. (2017). El habitus. Una revisión analítica. Revista Internacional de Sociología, 75 (3), e074 DOI: http://dx.doi.org/10.3989/ ris.2017.75.3.15.115

Mauger, G. (2011). Préface de la deuxième édition y Postface. En K. Mannheim: Le problème des générations. Armand Colin.

Mauger, G. (2015). Agges et générations. La Découverte.

Oakley, A. (1972). Sex, Gender and Society. Temple Smith.

Ortega y Gasset, J. (2004-2010). Obras Completas. Tomos I-X, Taurus/Fundación Ortega y Gasset.

Passeron, J.-C. (2006). Le raisonnement sociologique. Un espace non-poppérien de l'argumentation. Albin Michel 
Piaget, J. (1979). Seis estudios de psicología. Seix Barral.

Sapiro, G. (2019). "Rethinking the Concept of Autonomy for the Sociology of Symbolic Goods". Biens Symboliques /Symbolic Goods, 4.

Wright, E. O. (2014). Construyendo utopías reales. Akal.

Wright, E. O. (2018). Comprender las clases sociales. Akal.

DOI: https://doi.org/10.15366/bp2021.28.006

Bajo Palabra. II Época. No28. Pgs: 135-154 
